\title{
Acute effect of resistance exercise performed at different intensities on urine loss in older women
}

\author{
DOI: https://doi.org/10.5114/pq.2018.75996
}

\author{
Enaiane Cristina Menezes', Janeisa Franck Virtuoso², André Luiz Demantova Gurjão³, Giovana Zarpellon Mazo1 \\ ${ }^{1}$ Santa Catarina State University, Florianópolis, SC, Brazil \\ ${ }^{2}$ Federal University of Santa Catarina, Araranguá, SC, Brazil \\ ${ }^{3}$ Federal University of São Francisco Valley, Petrolina, PE, Brazil
}

\section{Abstract}

Introduction. To evaluate the acute effect of resistance exercise performed at different intensities (moderate and vigorous) on urine loss in older women with mixed and stress urinary incontinence.

Methods. The total of 16 older women with urinary incontinence underwent 2 sessions of resistance exercises involving different muscle groups. In a balanced crossover design, 1 of the 2 exercise intensities (12 or 6 repetitions maximum, RM) was applied in each session. The pad test was used to assess urine loss in the 2 sessions, with a weight increase of $2 \mathrm{~g}$ as the criterion. Differences in the pad test results between the sessions were compared with the use of the Wilcoxon test.

Results. The mean pad weight was $0.69 \pm 0.94 \mathrm{~g}$ at the intensity of $12 \mathrm{RM}$ and $0.50 \pm 0.53 \mathrm{~g}$ at $6 \mathrm{RM}$. In accordance with the cut-off adopted $(2 \mathrm{~g})$, only 2 of the 16 women lost urine. No significant difference in the pad test results $(p=0.975)$ was observed between the 2 resistance exercise intensities.

Conclusions. Resistance exercise performed at different intensities (moderate and vigorous) did not cause urine loss in older women with urinary incontinence.

Key words: older adults, urinary incontinence, weight lifting

\section{Introduction}

Leakage of urine during physical activities, particularly high-impact exercise, has been reported in the literature [1, 2]. The prevalence of urine loss can reach up to $67 \%$ among young athletes, who report to leak urine during their activities [1]. This fact might be explained by pelvic floor muscle weakness in situations of increased intra-abdominal pressure [3]. Furthermore, Shaw et al. [4] reported a progressive increase in intra-abdominal pressure with more intense exercises. According to Da Roza [5], this type of exercise requires an increase in the contraction strength of the pelvic floor muscles to close the urogenital hiatus and to maintain urinary continence.

In an attempt to understand what occurs in pelvic floor muscles immediately after resistance (squatting) or strenuous aerobic exercise (jumping jacks, vertical jumps, and running up and down the stairs), Ree et al. [6] observed that the maximal voluntary contraction pressure was reduced by $24.4 \%$ immediately after exercise in women with stress urinary incontinence (UI). Furthermore, exercise could stretch and overload the pelvic floor muscles [3]. According to Nygaard et al. [7], the impact of physical exercise on UI is not well established in the literature and there might be risk factors or protective factors of this disorder.

Knowledge of the effects of exercise on urine loss is even more sparse with reference to the elderly female population. Although it is known that $\mathrm{UI}$ is associated with decreased mobility [8] and that older women performing physical exercise have better pelvic floor muscle function than their sedentary peers [9], it is necessary to determine whether older women with $\mathrm{UI}$ lose urine when performing resistance exercise at different intensities (moderate and vigorous). Therefore, the objective of this study was to evaluate the acute effect of resistance exercise performed at different intensities (moderate and vigorous) on urine loss in older women with mixed and stress UI.

\section{Subjects and methods}

\section{Study design and participants}

This was a crossover study in which 22 older women $(\geq 60$ years old) living in the metropolitan region of Florianópolis, SC, Brazil, were recruited intentionally. The criterion of inclusion was the presence of stress and/or mixed UI (urine loss at least once a month). Older women who only had urge incontinence or pelvic organ prolapse and who withdrew from the intervention because of external factors (travel and other social commitments) were excluded. The final sample consisted of 16 participants.

\section{Instruments and data collection}

The International Continence Society defines UI as any involuntary loss of urine [10]. Thus, the examined women were asked the following question: 'During the past year, did you lose urine (unintentionally into your panties) at least once a month?' If affirmative, the presence of UI symptoms was identified and the participants were interviewed to determine the type and frequency of urine loss.

Correspondence address: Enaiane Cristina Menezes, Universidade do Estado de Santa Catarina - Centro de Ciências da Saúde e do Esporte - Laboratório de Gerontologia, Rua Pascoal Simone, 358, Coqueiros, Florianópolis, SC, Brazil, e-mail: enaianemenezes@gmail.com 
The type of UI was verified by asking the following questions: (a) 'Do you lose urine on coughing, sneezing, exercising or lifting?' (b) 'Do you lose urine before reaching the toilet after feeling a strong urge to urinate or without noticing?' An affirmative answer to question (a) was defined as stress $\mathrm{UI}$ and to question (b) as urge UI. Mixed UI was determined in cases of an affirmative answer to both questions.

For the participants' characterization, sociodemographic data (age, marital status, education level, and current occupation) were obtained by interview.

The pad test was used to assess urine loss during resistance exercises. Each pad was weighed on precision scales before use and placed in the perineal region near the external urethral meatus. The participants were then asked to drink $500 \mathrm{ml}$ of water and to rest for 30 minutes. After this period, the subjects underwent the resistance exercise session. At the end of exercise, the pad was removed and weighed again. The difference between the initial and final weight of $2 \mathrm{~g}$ was defined as urine loss during exercise [11]. On the day of the pad test application, the women were asked not to consume certain foods, such as citric fruit, caffeine, or tea.

\section{Experimental design}

Figure 1 shows the experimental protocol, which was divided into 7 steps:

(1) Familiarization: The objective of this step was to familiarize the participants with the execution of the range of motion, breathing, and adequate pace of movement of each exercise. A metronome set at the speed of $34 \mathrm{bpm}$ was used to control the pace of movement. The participants were asked to complete one phase of the exercise (concentric or eccentric) at each metronome beep. With respect to breathing, the women were instructed to inspire during the eccentric phase and expire during the concentric phase of the exercise. This step had a duration of 2-4 sessions.

(2) Determination of load reproducibility at 12RM (moderate intensity): Repetition maximum (RM) tests were performed to define the loads of each participant for the different resistance exercises (fly, horizontal leg press, lat pull down, adductor machine, triceps pulley, and biceps pulley) in the target zone of 12RM, in accordance with Gurjão et al. [12].

For the target zone of $12 \mathrm{RM}$, the participants were asked to perform the maximum number of repetitions possible with a load subjectively defined by the researcher (trial and error). If the number of repetitions exceeded $15 \mathrm{RM}, 1 \mathrm{~kg}$ was

added for each 2 excess repetitions. If the number of repetitions was less than 10RM, the load was adjusted by trial and error. During the test, the maximum of 2 attempts of load definition were made for each exercise, with a resting interval of 10 minutes between the attempts.

The participants were asked to perform the repetitions at the speed of 2 seconds for the concentric phase and 2 seconds for the eccentric phase, using a metronome. The tests were repeated after a minimum period of 48 hours, which allowed to avoid errors in the definition of training loads and to verify reproducibility. For the exercises performed at the intensity of 12RM, the intra-class correlation coefficients (ICC) were higher than 0.90 (Table 1). This step had a duration of $2-4$ sessions.

(3) Determination of load reproducibility at 6RM (vigorous intensity): This step had the same objective and used the same procedures as those adopted for the target zone of $12 \mathrm{RM}$. The difference in the definition of training loads in the target zone of $6 \mathrm{RM}$ was that if the number of repetitions exceeded 10RM, $1 \mathrm{~kg}$ was added for each 2 excess repetitions. The ICC values were higher than 0.70 (Table 1). This step had a duration of $2-4$ sessions.

(4) Randomization of the participants: Before the interventions, the women participating in the study were ran-

Table 1. Intra-class correlation coefficients (ICC) for load reproducibility

\begin{tabular}{|l|c|}
\hline Exercise & ICC \\
\hline Fly 12RM & 0.982 \\
\hline Leg press 12RM & 0.961 \\
\hline Lat pull down 12RM & 0.965 \\
\hline Adductor 12RM & 0.949 \\
\hline Triceps 12RM & 0.979 \\
\hline Biceps 12RM & 0.966 \\
\hline Fly 6RM & 0.787 \\
\hline Leg press 6RM & 0.910 \\
\hline Lat pull down 6RM & 0.858 \\
\hline Adductor 6RM & 0.794 \\
\hline Triceps 6RM & 0.930 \\
\hline Biceps 6RM & 0.855 \\
\hline
\end{tabular}

$\mathrm{RM}$ - repetition maximum

6

7

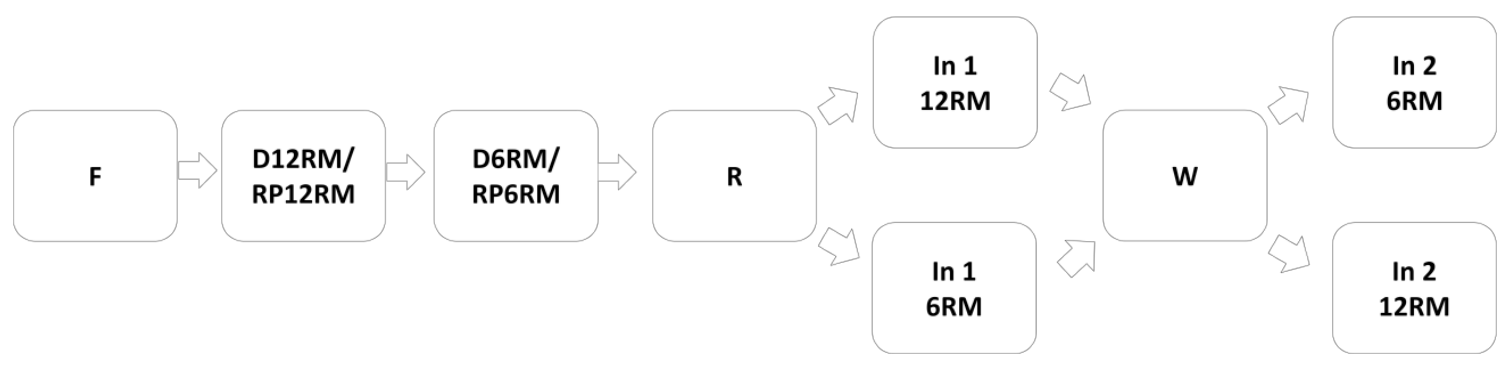

F - familiarization, RM - repetition maximum, D12RM/RP12RM - determination and reproducibility of the 12 RM load, D6RM/RP6RM - determination and reproducibility of the 6RM load, R - randomization, In1 - intervention 1, W - washout period (crossover design), In2 - intervention 2 
domized with regard to the intensity of resistance exercise, i.e., if a subject was randomized to the vigorous intensity (6RM), her first intervention was performed at this intensity and the second at the moderate intensity (12RM) and vice versa.

(5) Intervention 1: The objective of this step was to evaluate urine loss (pad test) of the participants during the resistance exercise session (acute effect) in accordance with the intensity (12RM or 6RM) selected for the first intervention. This step had a duration of 1 session.

For the moderate intensity, the participants performed 3 sets in the zone of $12 \mathrm{RM}$ with the load defined in the test, with a resting interval of 60 seconds between the sets and the speed of 2 seconds for the concentric phase and 2 seconds for the eccentric phase.

For the vigorous intensity, the women performed 3 sets in the zone of $6 \mathrm{RM}$ with the load defined in the test, with a resting interval of 60 seconds between the sets and the speed of 2 seconds for the concentric phase and 2 seconds for the eccentric phase.

The resistance exercises were performed in the following sequence: fly, horizontal leg press, lat pull down, adductor machine, triceps pulley, biceps pulley, and abdominal crunch. The adequate loads defined in steps 2 and 3 allowed fatigue (technical failure) to occur close to the target zone. Abdominal crunch was the only exercise not applied in steps 2 and 3 . For both intensities, 3 sets of 10RM without loads were performed. This step had a duration of 1 session.

(6) Washout period (crossover design): The objective of this step was to avoid a carryover effect in which the first session of resistance exercise interferes with the second session. A washout period of 4-7 days between one intervention and the other, performed at different intensities (12RM or 6RM), was adopted.

(7) Intervention 2: This step had the same objective and used the same procedures as those applied in intervention 1, except that the participants performed the resistance exercise session with a different intensity (12RM or 6RM) than in intervention 1. This step had a duration of 1 session.

The participants were recruited in accordance with the inclusion criteria by an external researcher. The researcher responsible for the load determinations and training sessions was unaware of the severity of urine loss symptoms.

\section{Data analysis}

The data were stored and analysed with the Statistical Package for the Social Sciences (SPSS, IBM), version 20.0. The categorical variables are reported as simple frequency and percentage, and measures of position and dispersion were used for numerical variables. The distribution of the data was verified by the Shapiro-Wilk test.

The ICC was used to verify the test-retest reproducibility of the loads applied at the intensities of 12RM and 6RM. For inferential analysis, the Wilcoxon test allowed to evaluate differences in the pad test results between the 12RM and $6 \mathrm{RM}$ intensities. The paired $t$-test was used to verify differences between the loads applied at the intensities of 12RM and 6RM. The level of significance of $p<0.05$ was adopted for all tests.

\section{Ethical approval}

The research related to human use has been complied with Resolution 466/2012 of the National Health Council, has followed the tenets of the Declaration of Helsinki, and has been approved by the Ethics in Research Committee of the
Santa Catarina State University, under protocol number 498.443. The study was registered in the Brazilian Registry of Clinical Trials UTN: U1111-1149-2398.

\section{Informed consent}

Informed consent has been obtained from all individuals included in this study.

\section{Results}

The mean age of the participants $(n=16)$ was $69.69 \pm$ 6.45 years. Regarding sociodemographic data, $37.5 \%(n=6)$ of the women had complete elementary education, $43.8 \%$ $(n=7)$ were married, and $68.8 \%(n=11)$ were retired. Mixed UI was present in $87.5 \%(n=14)$ of the women and stress UI in $12.5 \%(n=2)$.

The mean number of sessions in the process of the study (from familiarization to intervention 2) was $11.92 \pm 1.97$. As can be seen in Table 2, a significant difference between the exercise intensities (12RM and 6RM) performed by the older women with UI was observed for all resistance exercises.

The mean urine loss (pad test result) during the exercise session was $0.69 \pm 0.94 \mathrm{~g}$ for the moderate intensity $(12 \mathrm{RM})$ and $0.50 \pm 0.53 \mathrm{~g}$ for the vigorous intensity $(6 \mathrm{RM})$. With the consideration of the cut-off adopted ( $2 \mathrm{~g})$, among the 16 older women studied, only 1 lost urine at the intensity of $12 \mathrm{RM}(4.09 \mathrm{~g})$ and another at the intensity of $6 \mathrm{RM}$

Table 2. Comparison of loads between different intensities (12RM and 6RM) of resistance exercise $(n=16)$

\begin{tabular}{l|c|c|c}
\hline \multirow{2}{*}{ Exercise } & \multicolumn{2}{|c|}{ Load } & \multirow{2}{*}{$p$ value } \\
\cline { 2 - 3 } & $12 \mathrm{RM}$ & $6 \mathrm{RM}$ & \\
\hline Fly & $11.12 \pm 3.46$ & $15.12 \pm 3.55$ & $<0.001$ \\
\hline Leg press & $31.06 \pm 5.94$ & $37.81 \pm 7.44$ & $<0.001$ \\
\hline Lat pull down & $18.68 \pm 4.97$ & $24.62 \pm 5.09$ & $<0.001$ \\
\hline Adductor & $22.75 \pm 4.12$ & $28.93 \pm 4.78$ & $<0.001$ \\
\hline Triceps & $15.31 \pm 4.92$ & $20.75 \pm 5.11$ & $<0.001$ \\
\hline Biceps & $10.18 \pm 3.33$ & $16.25 \pm 3.71$ & $<0.001$ \\
\hline
\end{tabular}

Values are presented as mean \pm standard deviation

$\mathrm{RM}$ - repetition maximum



ULA - upper limit of agreement; LLA - lower limit of agreement Figure 2. Pad test results for the intensities of $12 \mathrm{RM}$ and $6 \mathrm{RM}(n=16)$ 


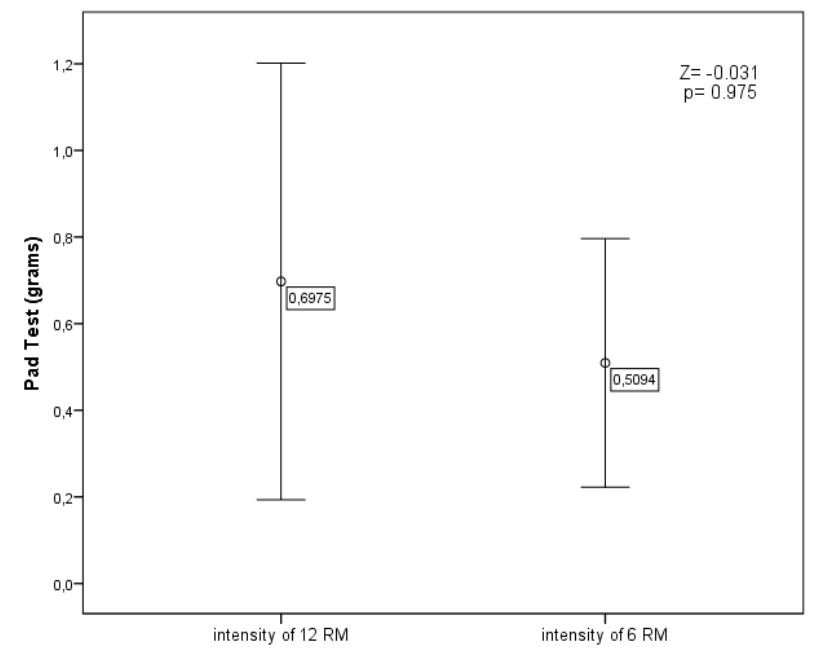

Z - Wilcoxon test; $\mathrm{p}$ - level of significance

Figure 3. Comparison of urine loss at different exercise intensities $(n=16)$

(2.20 g). In addition, Figure 2 illustrates the agreement between pad weights at the 2 exercise intensities.

No significant difference $(p=0.486)$ in mean pad weights was observed at the exercise intensities tested (Figure 3), thus proving the null hypothesis of this experiment that resistance exercise at different intensities does not cause urine loss in older women with UI.

\section{Discussion}

In the presented study, urine loss during resistance exercise was observed in only 2 older women with UI (1 at the intensity of $12 \mathrm{RM}$ and 1 at the intensity of $6 \mathrm{RM})$. Although we did not use a vaginal transducer to measure intra-abdominal pressure during exercise at different intensities, these findings suggest that resistance exercise provides indirect protection, preventing urine loss in women with UI.

The impact of physical exercise on the pelvic floor has been described as a risk factor for the development of UI in research on the prevalence of urine loss in female athletes $[1,2,13]$. In a study of Da Roza et al. [13], 72.7\% of female trampolinists reported urine loss during exercise. Ree et al. [6], submitting women to resistance and strenuous aerobic exercise, observed the mean urine loss in the pad test of $3.8 \mathrm{~g}$. Scientific evidence of the impact of different exercise intensities is needed for the population of older women because UI is a multifactorial phenomenon and physical exercise remains a behavioural and modifiable factor of this condition [14].

Stress UI, a disorder affecting all older women of this study, occurs in situations of increased intra-abdominal pressure [10]. According to Shaw et al. [4], the intra-abdominal pressure rises with increasing intensity of the activity; for example, walking at an inclination of $7 \%$ results in an intra-abdominal pressure of $35 \mathrm{~cm} \mathrm{H}_{2} \mathrm{O}$ compared with $66.5 \mathrm{~cm} \mathrm{H}_{2} \mathrm{O}$ for running and $41.6 \mathrm{~cm} \mathrm{H} \mathrm{H}_{2} \mathrm{O}$ for cycling. In this case, strenuous exercise can lead to overload and weakening of the pelvic floor muscles [3], as well as muscle fatigue immediately after the activity [6].

In addition to an increase of intra-abdominal pressure in certain physical activities, this rise can also be caused by obesity [15]. In this respect, waist circumference has been
$[8,16]$. Intervention studies have demonstrated a decrease of up to $47 \%$ in episodes of urine loss with a reduction in body weight [17]. This discussion on the increase in intra-abdominal pressure is in accordance with the theoretical model proposed by Nygaard et al. [7], in which exercise can affect the pelvic floor differently, acting on this structure in a bidirectional manner (positive and negative). Thus, the benefits of exercise or physical activity on the pelvic floor are limited. However, these authors stated that the activities could reduce body weight and increase muscle strength, and in this way contribute to the reduction of UI symptoms [7].

In the elderly population, resistance exercise has been reported to be beneficial for physical $[18,19]$ and psychological health [20], as well as to reduce physical disabilities [21]. High-intensity exercises (> 70\% 1RM) lead to greater gains in muscle strength [22] and bone mass in older adults [18]. In the present study, lower mean pad weights during exercise were observed for the higher intensity (6RM).

In addition to the acute effect on urine loss, some clinical trials [23] applying a 3-month intervention program consisting of exercises to strengthen the pelvic floor, lower limb, abdominal muscles, latissimus dorsi, and rhomboid muscles demonstrated significant improvement of UI, reducing the frequency of urine loss and curing these symptoms. Another important aspect is that UI not only impacts on the social life of older women [24] but also is related to lower handgrip strength and slower gait speed [25]. Taken together, the findings suggest that resistance exercise could be an accessible tool to improve the symptoms of urine loss, as well as other physical aspects relevant to the health of older women.

\section{Limitations}

Physical exercise is known to cause an increase in intraabdominal pressure. However, this study did not apply vaginal transducers to measure the number of pressure peaks caused by the different exercises in the sessions. In addition, the use of medications such as diuretics and sedatives was not controlled in this study.

\section{Conclusions}

In the present study, resistance exercise performed at different intensities (moderate and vigorous) did not cause urine loss in most of the older women with Ul. Although resistance exercise can increase intra-abdominal pressure as documented in the health literature, women with UI in the presented study did not suffer from acute effects of increased intra-abdominal pressure in the pelvic floor caused by exercise. Further research should investigate the intra-abdominal pressure that resistance exercise can exert on the structures of the pelvic floor in older women using devices such as vaginal transducers. In addition, experimental designs exploring the long-term effects of resistance exercise in the elderly female population with UI are needed.

\section{Disclosure statement}

No author has any financial interest or received any financial benefit from this research.

\section{Conflict of interest}

The authors state no conflict of interest. 


\section{References}

1. Nygaard IE, Thompson FL, Svengalis SL, Albright JP. Urinary incontinence in elite nulliparous athletes. Obstet Gynecol. 1994;84(2):183-187; doi: 10.1016/0020-7292 (95)90255-4.

2. Thyssen HH, Clevin L, Olesen S, Lose G. Urinary incontinence in elite female athletes and dancers. Int Urogynecol J Pelvic Floor Dysfunct. 2002;13(1):15-17; doi: $10.1007 / \mathrm{s} 001920200003$.

3. Bø K. Urinary incontinence, pelvic floor dysfunction, exercise and sport. Sports Med. 2004;34(7):451-464; doi: 10.2165/00007256-200434070-00004.

4. Shaw JM, Hamad NM, Coleman TJ, Egger MJ, Hsu Y, Hitchcock R, et al. Intra-abdominal pressures during activity in women using an intra-vaginal pressure transducer. J Sports Sci. 2014;32(12):1176-1185; doi: 10.1080/ 02640414.2014 .889845$.

5. Da Roza T. Urinary incontinence in young nulliparous women: the effects of different levels of physical activity (thesis). Porto: Universidade do Porto; 2015.

6. Ree ML, Nygaard I, Bø K. Muscular fatigue in the pelvic floor muscles after strenuous physical activity. Acta Obstet Gynecol Scand. 2007;86(7):870-876; doi: 10.1080/ 00016340701417281.

7. Nygaard I, Shaw J, Egger MJ. Exploring the association between lifetime physical activity and pelvic floor disorders: study and design challenges. Contemp Clin Trials. 2012;33(4):819-827; doi: 10.1016/j.cct.2012.04.001.

8. Bresee C, Dubina ED, Khan AA, Sevilla C, Grant D, EiIber KS, et al. Prevalence and correlates of urinary incontinence among older community-dwelling women. Female Pelvic Med Reconstr Surg. 2014;20(6):328-333; doi: 10.1097/SPV.0000000000000093.

9. Virtuoso JF, Mazo GZ, Menezes EC. Urinary incontinence and perineal muscle function in physically active and sedentary elderly women. Braz J Phys Ther. 2011;15(4): 310-317; doi: 10.1590/S1413-35552011005000014.

10. Haylen BT, de Ridder D, Freeman RM, Swift SE, Berghmans B, Lee J, et al. An International Urogynecological Association (IUGA)/International Continence Society (ICS) joint report on the terminology for female pelvic floor dysfunction. Neurourol Urodyn. 2010;29:4-20; doi: 10.1002/nau.20798.

11. Ghoniem G, Stanford E, Kenton K, Achtari C, Goldberg R, Mascarenhas T, et al. Evaluation and outcome measures in the treatment of female urinary stress incontinence: International Urogynecological Association (IUGA) guidelines for research and clinical practice. Int Urogynecol J Pelvic Floor Dysfunct. 2008;19(1):5-33; doi: 10.1007/ s00192-007-0495-5.

12. Gurjão AL, Gobbi LT, Carneiro NH, Gonçalves R, Ferreira de Moura R, Cyrino ES, et al. Effect of strength training on rate of force development in older women. Res $Q$ Exerc Sport.2012;83(2):268-275;doi:10.1080/02701367.2012. 10599857.

13. Da Roza T, Brandão S, Mascarenhas T, Jorge RN, Duarte JA. Volume of training and the ranking level are associated with the leakage of urine in young female trampolinists. Clin J Sport Med. 2015;25(3):270-275; doi: 10.1097/JSM.0000000000000129.

14. Grewar H, McLean L. The integrated continence system: a manual therapy approach to the treatment of stress urinary incontinence. Man Ther. 2008;13(5):375-386; doi: 10.1016/j.math.2008.01.003.

15. Dursun M, Otunctemur A, Ozbek E, Sahin S, Besiroglu H,
Koklu I. Stress urinary incontinence and visceral adipose index: a new risk parameter. Int Urol Nephrol. 2014;46(12): 2297-2300; doi: 10.1007/s11255-014-0832-9.

16. Devore EE, Minassian VA, Grodstein F. Factors associated with persistent urinary incontinence. Am J Obstet Gynecol. 2013;209(2):145.e1-145.e6; doi: 10.1016/j. ajog.2013.05.002.

17. Wing RR, West DS, Grady D, Creasman JM, Richter HE, Myers D, et al. Effect of weight loss on urinary incontinence in overweight and obese women: results at 12 and 18 months. J Urol. 2010;184(3):1005-1010; doi: 10.1016/j.juro.2010.05.031.

18. Karabulut M, Bemben DA, Sherk VD, Anderson MA, Abe T, Bemben MG. Effects of high-intensity resistance training and low-intensity resistance training with vascular restriction on bone markers in older men. Eur J Appl Physiol. 2011;111(8):1659-1667; doi: 10.1007/s00421010-1796-9.

19. Cadore EL, Pinto RS, Bottaro M, Izquierdo M. Strength and endurance training prescription in healthy and frail elderly. Aging Dis. 2014;5(3):183-195; doi: 10.14336/ AD.2014.0500183.

20. Singh NA, Stavrinos TM, Scarbek Y, Galambos G, Liber C, Fiatarone Singh MA. A randomized controlled trial of high versus low intensity weight training versus general practitioner care for clinical depression in older adults. J Gerontol A Biol Sci Med Sci. 2005;60(6):768-776; doi: 10.1093/gerona/60.6.768.

21. Liu C, Latham N. Can progressive resistance strength training reduce physical disability in older adults? A meta-analysis study. Disabil Rehabil. 2011;33(2):87-97; doi: 10.3109/09638288.2010.487145.

22. Raymond MJ, Bramley-Tzerefos RE, Jeffs KJ, Winter A, Holland AE. Systematic review of high-intensity progressive resistance strength training of the lower limb compared with other intensities of strength training in older adults. Arch Phys Med Rehabil. 2013;94(8):1458-1472; doi: 10.1016/j.apmr.2013.02.022.

23. Kim H, Yoshida H, Suzuki T. The effects of multidimensional exercise treatment on community-dwelling elderly Japanese women with stress, urge, and mixed urinary incontinence: a randomized controlled trial. Int J Nurs Stud. 2011;48(10):1165-1172; doi: 10.1016/j.jinurstu.2011.02.016.

24. Elbiss MH, Osman N, Hammad FT. Social impact and healthcare-seeking behavior among women with urinary incontinence in the United Arab Emirates. Int J Gynaecol Obstet. 2013;122(2):136-139; doi: 10.1016/j.ijgo.2013. 03.023.

25. Kim H, Yoshida H, Hu X, Saito K, Yoshida Y, Kim M, et al. Association between self-reported urinary incontinence and musculoskeletal conditions in community-dwelling elderly women: a cross-sectional study. Neurourol Urodyn. 2015;34(4):322-326; doi: 10.1002/nau.22567. 